\title{
Análise de percepções e procedimentos algébricos de estudantes da Educação Básica*
}

\section{Analysis of Elementary School students' algebraic perceptions and procedures}

\author{
Neiva Ignês Grando** \\ Sandra Mara Marasini***
}

\begin{abstract}
Resumo: Essa pesquisa objetiva verificar como estudantes da Educação Básica se percebem em relação à matemática e, ao mesmo tempo, analisar os procedimentos utilizados para resolver questões algébricas. Os sujeitos, estudantes de $8^{a}$ série do Ensino Fundamental, $1^{\circ}$ e $3^{\circ}$ anos do Ensino Médio, de duas escolas públicas de Passo Fundo/RS, responderam a um instrumento contendo questões relacionadas à sua própria percepção das aulas da disciplina, à matemática e a conteúdos algébricos. A análise foi baseada principalmente em autores das áreas da Educação Matemática e da psicologia histórico-cultural. Verificamos que, mesmo entre os estudantes que afirmaram sentirem-se alegres ou felizes com a ideia de terem uma aula de matemática, muitos apresentaram dificuldades de aprendizagem de conteúdos algébricos, reveladas pelos procedimentos utilizados. Concluímos que é necessário elaborar propostas com sequências didáticas, fundamentadas matemática e pedagogicamente, que efetivamente potencializem a apropriação de significados dos conceitos abordados e a sua aplicação em diferentes situações.
\end{abstract}

Palavras-chave: Educação Básica. Percepções de estudantes. Procedimentos algébricos.

\begin{abstract}
This study aims to verify how students in elementary school see themselves in relation to mathematics and, at the same time, analyze the procedures used to solve algebraic tasks. These students in the $8^{\text {th }}$ year of elementary school, and first and third years of high school, from two State schools in Passo Fundo/RS, answered a questionnaire about their own perceptions of the mathematics lessons, the subject mathematics and algebraic content. The analysis was based mainly on authors from the mathematical education and the historic-cultural psychology areas. It was verified that even among students who claimed to be happy with the idea of having mathematics classes several presented learning difficulties regarding algebraic contents, revealed by the procedures employed. It was concluded that it is necessary to design proposals

\footnotetext{
"Uma primeira versão, com partes desse texto, foi apresentada na XIII Conferência Interamericana de Educación Matemática - Recife/PE - 2011.

** Professora da Universidade de Passo Fundo. E-mail: <neiva@upf.br>

*** Professora da Universidade de Passo Fundo. E-mail: <marasini@upf.br>
} 
with didactic sequences, mathematically and pedagogically based, which can efficiently optimize the appropriation of meaning from the concepts approached and their application in different situations.

Keywords: Basic education. Students' perceptions. Algebraic procedures.

\section{Introdução}

Diante da complexidade do processo de ensino-aprendizagem, compreender os sentimentos, identificar e acompanhar o processo de atribuição de sentido dos estudantes em relação aos conceitos matemáticos firma-se como uma necessidade para a avaliação e (re)elaboração das propostas pedagógicas de Educação Matemática.

Temos observado em nossas práticas pedagógicas, especialmente em disciplinas que abordam a metodologia do ensino da matemática, que muitos acadêmicos trazem dificuldades de seus estudos da Educação Básica, principalmente no que se refere à utilização dos fundamentos da matemática. Esse fato se evidencia tanto para resolver problemas como para elaborar sequências didáticas para os estágios supervisionados no Ensino Fundamental e médio. Alguns livros didáticos corroboram para esse fato, uma vez que suas propostas dificultam a verdadeira formação de conceitos, principalmente pela utilização de macetes.

Nesse contexto, emergem duas preocupações básicas: como estudantes do Ensino Fundamental e Médio se sentem em relação à matemática escolar? Como lidam com questões envolvendo conceitos algébricos?

Para melhor compreender a complexidade dessas questões, desenvolvemos uma pesquisa com o objetivo de verificar como os estudantes se sentem em relação à matemática e que tipos de procedimentos utilizam para resolver questões matemáticas, especialmente de cunho algébrico. A análise tem como finalidade repensar a prática e subsidiar o processo de elaboração de propostas pedagógicas para a matemática na Educação Básica.

\section{Fundamentos da pesquisa}

A formação de conceitos, as potencialidades e as dificuldades inerentes ao processo de ensino-aprendizagem têm ocupado um espaço cada vez mais significativo nas pesquisas e debates entre os educadores matemáticos.

Em relação a esse processo, com base nas concepções teóricas de Vygotsky (1996, p. 78, tradução nossa), podemos observar que nos apropriamos do significado de um conceito quando "chegamos a conhecer o objeto em todos seus nexos e relações", quando "sintetizamos verbalmente essa diversidade em uma imagem total mediante múltiplas definições". 
Para Vygotsky (1993, p. 176, tradução nossa), o conceito forma-se durante uma operação intelectual, em um processo no qual "participam todas as funções intelectuais em uma combinação original, cujo fator central é o uso funcional da palavra como meio de orientação deliberada da atenção, da abstração, da seleção de atributos e de sua síntese e simbolização com ajuda do signo". Assim, a apropriação do significado de um conceito tem como pressuposto a atribuição de sentido pelo sujeito da aprendizagem.

Ao analisar os fatores de desenvolvimento do adolescente, Vygotsky (1993, p. 133, tradução nossa) enfatiza que “onde o meio não apresenta ao adolescente as tarefas adequadas, não lhe estabelece exigências novas, não desperta nem estimula o desenvolvimento de seu intelecto mediante novas metas, o pensamento do adolescente não desenvolve todas suas possibilidades, não chega a alcançar as formas superiores ou as alcança com grande atraso."

Nessa concepção, diante de desafios, a atribuição de sentido é um processo no qual os estudantes podem apresentar dificuldades ou mesmo se depararem com obstáculos à aprendizagem. Segundo Vergnaud (1989), na aprendizagem de matemática é possível identificar dificuldades de natureza diversa e, por isso, é importante que façamos uma análise detalhada de cada situação para distinguir os obstáculos das outras dificuldades conceituais. Este autor distingue dois tipos de dificuldades: aquelas em que "existem saltos do pensamento, sem que esses saltos entrem violentamente em contradição com as concepções e as competências anteriormente formadas" e aquelas que "formam obstáculos epistemológicos importantes e duráveis", os quais precisam ser analisados pelo estudante "para mudar de concepção e compreender a relação da concepção nova a formar com a anterior" (VERGNAUD, 1989 apud GRANDO, 1995, p. 111).

Para Brousseau (1983 apud GRANDO, 1995, p. 110), “a identificação e a caracterização de um obstáculo são essenciais para a análise e para a construção de situações didáticas", ressaltando que um obstáculo cognitivo se manifesta através de erros. Da classificação que o autor faz, destacamos os obstáculos didáticos, que podem ser determinados pela metodologia utilizada em sala de aula, a qual geraria conhecimentos errôneos ou incompletos constituindo-se em obstáculos para a formação de determinados conceitos científicos escolares, assim como os obstáculos epistemológicos, que são inerentes ao próprio conhecimento.

Obstáculos didáticos podem ser identificados quando o professor desenvolve os conteúdos matemáticos valendo-se de macetes, de que os estudantes se utilizam para resolver uma equação, por exemplo. A ideia que fica para o estudante é a de que "quando um termo passa para o outro lado, muda de sinal". Não compreendendo essa "regra", muitos estudantes a "decoram" e, no caso de "passa para o outro lado, dividindo ou multiplicando", também trocam de sinal, 
o que facilmente os leva ao erro. A regra que vigorava no contexto de adição e subtração não vigora para a multiplicação e divisão. Um conhecimento anterior inadequado num contexto leva a uma generalização também inadequada matematicamente num outro contexto. A solução de uma equação de $1^{\circ}$ grau, por exemplo, utilizando os princípios matemáticos, aditivo e multiplicativo, além de evitar erros, forneceria elementos ao estudante para a compreensão do processo de resolução de uma equação de $1^{\circ}$ grau e para a generalização do significado de resolução de uma equação.

Obstáculos epistemológicos podem ser identificados, por exemplo, na operação de multiplicação com números racionais. Quando o conjunto dos números naturais é definido como o universo, em geral o estudante fica com a representação mental de que ao multiplicar obtém-se um número maior (com exceção da multiplicação pela unidade ou por zero). Ao se deparar com multiplicação de racionais, seja na forma fracionária ou decimal, a concepção que era válida para os naturais não é mais válida nesse conjunto universo, ou seja, o conjunto dos números racionais. Assim, com base em Brousseau (1983 apud GRANDO, 1995, p. 116), "uma concepção adequada para uma situação torna-se inadequada para outra, gerando uma dificuldade que pode constituir-se em obstáculo para a aprendizagem”. Neste caso específico, há um obstáculo epistemológico a transpor, com ampliação de conhecimento, ou seja, com uma nova concepção em relação à multiplicação num outro conjunto numérico, o dos racionais.

Em relação à linguagem algébrica, historicamente houve dificuldades de representação, sendo que, numa primeira fase, a da álgebra terminológica, eram empregadas somente palavras, no seu próprio sentido simbólico; numa segunda fase, a sincopada, foram introduzidas algumas abreviações de palavras; esse percurso foi evoluindo até chegar à linguagem atual da álgebra, a simbólica. (IFRAH, 1997, p. 560).

Vygotsky (1993, p. 198, tradução nossa) refere-se à álgebra como uma linguagem que "eleva a um nível superior o pensamento aritmético, permitindo compreender qualquer operação aritmética como um caso particular de uma operação algébrica, proporcionando uma visão mais livre, mais abstrata e generalizada e com isso mais profunda e rica do que as operações com quantidades concretas."

Nesse sentido, com base na concepção desse autor, compreender a álgebra significa entender o que ela representa além da aplicação de suas operações e propriedades, ou seja, conhecer seus fundamentos, com base em uma generalização de nível maior, ou seja, o conhecimento gerado constituindo-se em generalização de generalizações anteriormente formadas. (VYGOTSKY, 1993, p. 199). 
Sobre equações lineares, Robayna et al. (1996, p. 45-46, tradução nossa) mostram sua forma geral e o processo atual de resolução utilizando os fundamentos da matemática: "Uma equação linear é uma expressão da forma $a x+b=c$, onde $x$ é a incógnita e $a, b$ e $c$ são números conhecidos. Para obter a solução procedemos assim: somamos o oposto de $b$ nos dois membros:

$a x+b+(-b)=c+(-b)$

$a x=c-b$

multiplicamos pelo inverso de $a$ :

$\frac{1}{a} a x=\frac{1}{a}(c-b)$

e obteremos a solução de $x$ :

$x=\frac{c-b}{a} . "$

Sobre equações quadráticas, os autores mostram que "Uma equação de segundo grau com uma incógnita é uma expressão da forma $a x^{2}+b x+c=0$, onde $x$ é a incógnita e $a, b$ e $c$ são números conhecidos com $a \neq 0$ ". Assim, "resolver esta equação é encontrar os valores de $x$ que a satisfazem." (ROBAYNA et al., 1996, p. 50, tradução nossa).

Ainda destacam, aritmeticamente, a fórmula atualmente utilizada: $x=\frac{-b \pm \sqrt{b^{2}-4 a c}}{2 a}$. (ROBAYNA et al., 1996, p. 51).

Com isso, enfatizamos a importância dos fundamentos da matemática como um dos princípios que deveríamos levar em consideração, tanto para a elaboração de uma proposta pedagógica como para seu desenvolvimento em sala de aula. (GRANDO; MARASINI, 2008).

Os resultados da pesquisa de Cury; Ribeiro e Müller (2011), envolvendo alunos de cursos de licenciatura em matemática, resolvendo uma questão sobre equações, apontam para esta necessidade: "A análise dos erros e a compreensão das dificuldades desses estudantes deve servir como alerta para que todos nós formadores de professores - tomemos consciência da importância de se discutir, nos cursos de licenciatura, conceitos matemáticos elementares, de um ponto de vista avançado." (CURY; RIBEIRO; MÜLLER, 2011, p. 155).

Nesse sentido, tanto a aprendizagem como o desenvolvimento do pensamento dependem em grande parte da escola, do tipo de proposta pedagógica desenvolvida em sala de aula, mas, sobretudo, dos motivos que levam estudantes e professores a participar de processos de ensino e de aprendizagem. 


\section{O processo de pesquisa}

Os sujeitos desta pesquisa são estudantes de duas escolas públicas de Passo Fundo/RS, compondo os seguintes grupos: duas turmas de $8^{a}$ série do Ensino Fundamental ${ }^{1}$, uma da escola da rede municipal (26 estudantes) e outra da escola da rede estadual de ensino (26 estudantes); uma turma de $1^{\circ}$ ano (23 estudantes) e uma de $3^{\circ}$ ano (18 estudantes), do Ensino Médio, da escola da rede estadual de ensino ${ }^{2}$.

Para obter informações junto aos estudantes da Educação Básica aplicamos um instrumento, por escrito, individualmente, contendo três tipos de questões: sobre como o estudante se percebe em relação à matemática, sobre a matemática e sobre o conteúdo matemático, propriamente dito.

No primeiro tipo de questão, os estudantes responderam sobre como se sentem quando sabem que terão aula de matemática e se eles têm facilidade para aprender matemática, com respectiva justificativa. No segundo tipo, como sabem quando um conteúdo é de álgebra, geometria ou aritmética e quais conteúdos de álgebra já haviam estudado. No terceiro tipo, as questões envolviam identificação de objetos algébricos - expressão algébrica e equação de $1^{\circ}$ grau com uma incógnita -, solução de equações de $1^{\circ}$ e $2^{\circ}$ graus, determinação de raízes e construção de gráficos cartesianos de funções de $1^{\circ}$ e $2^{\circ}$ graus.

O conteúdo matemático que compõe o referido instrumento já havia sido estudado pelos estudantes dos dois níveis de ensino. Na elaboração do instrumento optamos por inserir apenas questões básicas conhecidas como "exercícios matemáticos", propositadamente, para não haver interferência de possíveis dificuldades de interpretação de enunciados de problemas, apresentados em linguagem corrente.

Para identificar os sujeitos desta pesquisa, usou-se a letra inicial da palavra estudante, maiúscula, seguido de quatro algarismos, sendo que o primeiro indica a série ou ano (8 para $8^{\mathrm{a}}$ série; 1 para $1^{\circ}$ ano; 3 para $3^{\circ}$ ano), o segundo indica a escola ( 1 para a escola da rede municipal e 2 para a escola da rede estadual) e o terceiro e o quarto algarismos, indicam o aluno, classificado por ordem alfabética em sua respectiva turma. Por exemplo, $\mathrm{E}_{8104}$ identifica o estudante de $8^{\mathrm{a}}$ série, da escola municipal e quarto da lista de sua turma; $\mathrm{E}_{3215}$ identifica o estudante de $3^{\circ}$ ano, da escola estadual e décimo quinto de sua turma.

Para a análise dos dados, o conteúdo das respostas dos estudantes foi agrupado em três categorias: "percepção sobre si mesmos em relação à matemá-

\footnotetext{
${ }^{1}$ Ensino Fundamental de oito anos.

${ }^{2}$ A escola da rede municipal de ensino não oferece Ensino Médio.
} 
tica", "campos matemáticos e álgebra" e "classificação de objetos algébricos e resolução de equações e funções de $1^{\circ}$ e $2^{\circ}$ graus".

\section{Percepções e procedimentos matemáticos}

\section{Como os estudantes se percebem em relação à matemática}

Ao analisar como os alunos se percebem em relação à matemática, constatamos que 67,74\% dos estudantes da Educação Básica que participaram da pesquisa sentem-se alegres $(61,29 \%)$ ou felizes $(6,45 \%)$ quando se deparam com a ideia de terem uma aula de matemática; os outros sentem-se com medo $(25,80 \%)$ ou tristes $(6,45 \%)$.

Para Vygotsky (2001, p. 144), “[...] as aulas desses objetos [matemáticos] devem ir além dos secos esquemas lógicos e tornar-se objeto de trabalho não só do pensamento mas também do sentimento". Assim, perceber como o estudante está se sentindo nas aulas de matemática e procurar compreender suas razões pode contribuir para a aprendizagem e a sua formação mais geral, tanto emocional como intelectualmente.

Quanto à aprendizagem matemática, do total de estudantes, 23,76\% afirmam possuir facilidade para aprender, 62,37\% "mais ou menos" e 13,87\% manifestam não possuir facilidade. As justificativas das suas percepções são bastante diversificadas, em cada uma dessas opções, como podemos visualizar nos exemplos a seguir ${ }^{3}$ :

Facilidade

Na verdade não sei direito, mas eu pego a matéria, tento aprender e é por isso que tenho facilidade, porque tenho vontade de aprender. $\left(\mathrm{E}_{8124}\right)$.

Porque é fácil de entende, é só prestar atenção dai fica bem fácil de aprender. $\left(\mathrm{E}_{8224}\right)$.

Mais ou menos

A matemática para mim é mais complicada do que as outras matérias. $\left(\mathrm{E}_{8101}\right)$.

Por que, tem algumas coisas que eu tenho bastante dificuldade em aprender, e tenho medo de não saber fazer os exercícios dados pela professora. $\left(\mathrm{E}_{1215}\right)$.

Não facilidade

As vezes eu tenho medo das provas, en sei que tenho que passar de ano se esforçar aos montes e dai vem a dificuldade de matemática. $\left(\mathrm{E}_{1203}\right)$.

As vezes falta interesse mas quase sempre por não conseguir entende o que está sendo apresentado. As vežes me esqueço das explicações. $\left(\mathrm{E}_{3215}\right)$.

\footnotetext{
${ }^{3}$ A escrita dos estudantes foi mantida em sua forma original.
} 
Estabelecendo relação entre o sentimento frente a uma aula de matemática e a aprendizagem de seus conteúdos, verificamos que, entre os 64 estudantes que se sentem alegres ou felizes, apenas 22 deles afirmam possuir facilidade para aprender matemática; dos outros, 39 afirmam possuir "mais ou menos" facilidade, e 3 afirmam não possuir facilidade. Entre os estudantes cujo sentimento é medo ou tristeza diante da ideia de uma aula de matemática, em nenhum deles se percebe facilidade para aprender. Esse sentimento foi expresso por 29 estudantes (32,25\% do total de estudantes), dos quais 9 afirmam não ter facilidade e 20 ter "mais ou menos" facilidade para aprender matemática.

Em se tratando de Educação Matemática, para além do conteúdo matemático, é necessário que analisemos os sentimentos, as opiniões, as concepções dos estudantes em relação à matemática. Vygotsky (2001, p. 146) refere-se à importância do sentimento e da afetividade na educação, afirmando que "o aspecto emocional do indivíduo não tem menos importância do que outros aspectos e é objeto de preocupação da educação nas mesmas proporções em que o são a inteligência e a vontade". Em relação ao ensino e à aprendizagem, a concepção deste autor é de que "sempre que comunicamos alguma coisa a algum aluno devemos procurar atingir o seu sentimento. Isso se faz necessário não só como meio para melhor memorização e apreensão mas também como objetivo em si." (VYGOTSKY, 2001, p. 143).

$\mathrm{Na}$ discussão sobre seleção e organização dos conteúdos de matemática para o ensino fundamental, o documento dos Parâmetros Curriculares Nacionais destaca que "[...] os conteúdos envolvem explicações, formas de raciocínio, linguagens, valores, sentimentos, interesses e condutas.” (BRASIL, 1998, p. 49) e "as atitudes envolvem o componente afetivo - predisposição, interesse, motivação - que é fundamental no processo de ensino e aprendizagem. As atitudes têm a mesma importância que os conceitos e procedimentos, pois, de certa forma, funcionam como condições para que eles se desenvolvam.” (BRASIL, 1998, p. 50).

Assim, as emoções se constituem em elemento influenciador do comportamento, na medida em que, percebendo emoções positivas no ambiente escolar, o estudante é estimulado à aprendizagem e ao desenvolvimento cognitivo. Como a emoção é também responsável pelo comportamento do aluno, destacamos a concepção de Vygotsky (2001, p. 139) de que "toda emoção é um chamamento à ação ou uma renúncia a ela. Nenhum sentimento pode permanecer indiferente e infrutífero no comportamento. As emoções são esse organizador interno das nossas reações, que retesam, excitam, estimulam ou inibem essas ou aquelas reações." 
Nessa perspectiva, as diferentes emoções causam nos sujeitos sentimentos de amor ou de ódio pela matemática e pela realização de atividades que envolvam conceitos matemáticos, o que mostra que o emocional faz parte do sistema escolar, especialmente no processo de aprendizagem e de desenvolvimento do aluno na aprendizagem da matemática.

Com base nessas constatações e nas teorias, podemos afirmar que tanto as razões que desencadeiam o tipo de sentimento frente à possibilidade de ter ou estar em uma aula de matemática como a percepção individual de seu potencial de aprendizagem influenciam ou mesmo determinam o desempenho escolar dos estudantes da Educação Básica.

\section{Sobre os campos matemáticos e a álgebra}

Ao responderem a questão referente à diferenciação entre conteúdos algébricos, geométricos e aritméticos, um reduzido número de estudantes $(9,67 \%)$ forneceu respostas que tem alguma relação com a distinção entre conteúdos dos três campos matemáticos.

O campo matemático mais citado foi o da geometria, seguido da álgebra e da aritmética.

Quanto à geometria, fizeram referência a conteúdos como figuras geométricas, medidas de figuras e de ângulos; para a álgebra, "incógnitas representadas por letras", "cálculos com letras (incógnitas)", "conta que aparece letras com números" são respostas que têm alguma relação pertinente a esse campo. Já quanto ao campo da aritmética, apenas uma resposta contempla somente conhecimento aritmético: "tudo que envolve os numeros". Verificamos que, dos nove estudantes cujas respostas têm alguma relação com os campos matemáticos citados, dois deles se referem aos três campos, dois mencionam apenas álgebra e geometria, quatro só geometria e somente um faz referência à álgebra. Assim, observamos que apenas um dos estudantes conseguiu fazer uma distinção entre os três tipos de conteúdos: "Um conteúdo de álgebra envolve incógnitas representadas por letras, geometria figuras geométricas e aritmética tudo que envolve os números." $\left(\mathrm{E}_{1220}\right)$.

Em resumo, quanto à distinção entre conteúdos algébricos, geométricos e aritméticos, cabe salientar que, dentre as quatro turmas, apenas um estudante fez uma distinção adequada e oito o fizeram de forma incompleta; entre os demais, vinte e dois forneceram respostas sem nenhuma relação com o que foi solicitado, vinte e oito deixaram a questão em branco e trinta e quatro responderam que não lembravam ou não sabiam.

Especificamente sobre o campo algébrico, apenas quatro do total de estudantes $\left(\mathrm{E}_{8116} ; \mathrm{E}_{8117} ; \mathrm{E}_{1220} ; \mathrm{E}_{1222}\right)$ lembraram de conteúdos estudados, os quais se relacionam a expressões algébricas, equações e funções. 
Tomando como base o conhecimento algébrico, foco desta pesquisa, tínhamos a expectativa de que os estudantes tivessem, ao menos, a concepção de que álgebra envolve "números e letras". Quando nos referimos à concepção de álgebra estamos nos reportando às concepções identificadas por Usiskin (1995, p. 9-22): álgebra como aritmética generalizada, álgebra como um estudo de procedimentos para resolver certos tipos de problemas, álgebra como estudo de relações entre grandezas e álgebra como estudo das estruturas. Concepções que deveriam ser exploradas em sala de aula, pois, segundo os Parâmetros Curriculares Nacionais de matemática para o Ensino Fundamental, "existe um razoável consenso de que para garantir o desenvolvimento do pensamento algébrico o aluno deve estar necessariamente engajado em atividades que inter-relacionem as diferentes concepções da Álgebra." (BRASIL, 1998, p. 116). Esse documento sugere que "[...] ao planejar suas atividades, o professor procurará articular múltiplos aspectos dos diferentes conteúdos, visando a possibilitar a compreensão mais ampla que o aluno possa atingir a respeito dos princípios e métodos básicos do corpo de conhecimentos matemáticos [...].” (BRASIL, 1998, p. 53).

Consideramos que os estudos de álgebra deveriam iniciar desde os anos iniciais de escolarização paralelamente à aritmética e à geometria, a fim de possibilitar a distinção dos elementos de cada campo e, ao mesmo tempo, a inter-relação entre os conceitos dos diferentes campos. Nesse sentido, de acordo com os Parâmetros Curriculares Nacionais, "os adolescentes desenvolvem de forma bastante significativa a habilidade de pensar 'abstratamente', se lhes forem proporcionadas experiências variadas envolvendo noções algébricas, a partir dos ciclos iniciais, de modo informal, em um trabalho articulado com a Aritmética." (BRASIL, 1998, p. 117).

Além disso, "considerando que o estudo inicial dos conceitos algébricos no currículo escolar atual do ensino fundamental é apenas uma primeira etapa da educação algébrica, a continuidade do processo de formação desses conceitos deverá ser gradativa e de forma a proporcionar sempre o desenvolvimento do pensamento." (GRANDO; MARASINI, 2008, p. 116-117).

Nesse sentido, Miorim; Miguel e Fiorentini (1993, p. 88) conjecturam acertadamente que "o pensamento algébrico nos leva, portanto, a pensar que ele é um tipo especial de pensamento que pode se manifestar não apenas nos diferentes campos da matemática, como também em outras áreas do conhecimento." 


\section{Classificação de objetos algébricos e resolução de equações e funções de $1^{\circ}$ e $2^{\circ}$ graus}

Ao classificar objetos matemáticos como "expressões algébricas" ou "equações", verificamos que o número de estudantes que apresentou coerência em suas respostas, ou seja, classificou corretamente os três objetos matemáticos, representa, em média, menos de um terço de cada turma ou do total de participantes $(24,73 \%)$. Esses dados podem ser visualizados de forma mais específica na tabela a seguir:

Tabela 1 - Classificação correta de objetos matemáticos: número e porcentagem de estudantes por escola e por série ou ano

Identifique como "expressão algébrica" ou "equação": a) $2 x+3=6-3 x$

b) $3 \mathrm{x}-15$

c) $8=x+12$

\begin{tabular}{|c|c|c|c|c|c|c|c|}
\hline \multicolumn{2}{|c|}{ Escola 1} & \multicolumn{6}{|c|}{ Escola 2} \\
\hline \multirow{2}{*}{\multicolumn{2}{|c|}{$\begin{array}{l}8^{a} \text { série } \\
(n=26)\end{array}$}} & \multirow{2}{*}{\multicolumn{2}{|c|}{$\begin{array}{l}8^{a} \text { série } \\
(n=26)\end{array}$}} & \multirow{2}{*}{\multicolumn{2}{|c|}{$\begin{array}{l}1^{\circ} \text { ano } \\
(\mathrm{n}=23)\end{array}$}} & \multirow{2}{*}{\multicolumn{2}{|c|}{$\begin{array}{l}3^{\circ} \text { ano } \\
(n=18)\end{array}$}} \\
\hline & & & & & & & \\
\hline $\mathrm{n}^{\circ}$ & $\%$ & $\mathrm{n}^{\circ}$ & $\%$ & $\mathrm{n}^{\circ}$ & $\%$ & $\mathrm{n}^{\circ}$ & $\%$ \\
\hline 07 & 26,92 & 05 & 19,23 & 07 & 30,43 & 04 & 22,22 \\
\hline
\end{tabular}

Fonte: As autoras.

O conceito de equação é composto por vários outros conceitos matemáticos inter-relacionados. A própria formação de uma equação em sua representação algébrica traz subjacente a relação de equivalência de duas expressões algébricas. Desta forma, para o conceito de equação, é importante que o estudante diferencie expressões e sentenças, aritméticas e algébricas.

$\mathrm{Na}$ resolução de equações, constatamos que, em geral, os estudantes apresentaram dificuldades, sendo que um reduzido número de estudantes determinou o valor correto da incógnita para a equação de $1^{\circ}$ e de $2^{\circ}$ grau $(25,80 \%$ e $5,37 \%$, respectivamente).

A seguir apresentamos o panorama geral por turma. 
Tabela 2 - Resolução de equações: número de estudantes por escola e por turma

\begin{tabular}{|c|c|c|c|c|c|c|c|c|c|c|}
\hline \multirow{4}{*}{ 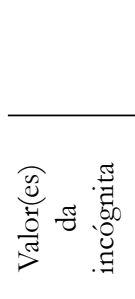 } & \multicolumn{10}{|l|}{ Resolva: } \\
\hline & \multicolumn{5}{|c|}{ a) $2 x+3=5 x-12$} & \multicolumn{5}{|c|}{ b) $x^{2}+6 x+9=0$} \\
\hline & \multirow{2}{*}{$\begin{array}{c}\text { Escola } 1 \\
8^{a} \text { série } \\
(n=26)\end{array}$} & \multicolumn{4}{|c|}{ Escola 2} & \multirow{2}{*}{$\begin{array}{l}\text { Escola } 1 \\
8^{a} \text { série } \\
(n=26)\end{array}$} & \multicolumn{4}{|c|}{ Escola 2} \\
\hline & & $\begin{array}{l}8^{a} \text { série } \\
(n=26)\end{array}$ & $\begin{array}{l}1^{\circ} \text { ano } \\
(\mathrm{n}=23)\end{array}$ & $\begin{array}{l}3^{\circ} \text { ano } \\
(\mathrm{n}=18)\end{array}$ & సٓ & & $\begin{array}{l}8^{a} \text { ano } \\
(n=26)\end{array}$ & $\begin{array}{l}1^{\circ} \text { ano } \\
(n=23)\end{array}$ & $\begin{array}{l}3^{\circ} \text { ano } \\
(n=18)\end{array}$ & 퓽 \\
\hline Correto & 02 & 06 & 08 & 08 & 24 & 00 & 03 & 00 & 01 & 04 \\
\hline Incorreto & 06 & 08 & 07 & 06 & 27 & 06 & 13 & 11 & 05 & 35 \\
\hline Total & 08 & 14 & 15 & 14 & 51 & 06 & 16 & 11 & 06 & 39 \\
\hline
\end{tabular}

Fonte: As autoras.

Vemos que, dos 51 estudantes $(54,83 \%$ do total) que tentaram resolver a equação de $1^{\circ}$ grau, 24 deles obtiveram a resposta correta; dos 39 estudantes $\left(41,93 \%\right.$ do total) que tentaram resolver a equação de $2^{\circ}$ grau, quatro deles obtiveram a resposta correta para o valor da incógnita.

Verificamos que, dos 93 estudantes, somente três deles $\left(\mathrm{E}_{8203} ; \mathrm{E}_{8220} ; \mathrm{E}_{3212}\right)$ obtiveram o valor correto para a incógnita nas duas equações.

Analisando os procedimentos dos estudantes que tentaram resolver a equação de $1^{\circ}$ grau com uma incógnita, percebemos que a grande maioria utilizou macetes. O procedimento mais utilizado foi aquele de "passar o termo para o outro lado mudando de sinal", o que inclusive provocou muitos erros com os sinais dos termos. Houve tentativa de resolver a equação utilizando os princípios matemáticos, aditivo e multiplicativo, por apenas quatro estudantes da Escola 1. No entanto, podemos afirmar que nem todos compreenderam o processo de obtenção de equações equivalentes com base na aplicação dos princípios. Provavelmente não compreenderam o papel dos próprios princípios para o processo de resolução. Vejamos alguns exemplos que mostram essas dificuldades, reveladas por erros nos procedimentos:

$1^{\circ}$ caso: erro na utilização dos princípios matemáticos

Equação: $2 \mathrm{x}+3=5 \mathrm{x}-12$ 
Solução $\left(\mathrm{E}_{8118}\right)$ :

\section{4) Resolva:}

a) $2 x+3=5 x-12$
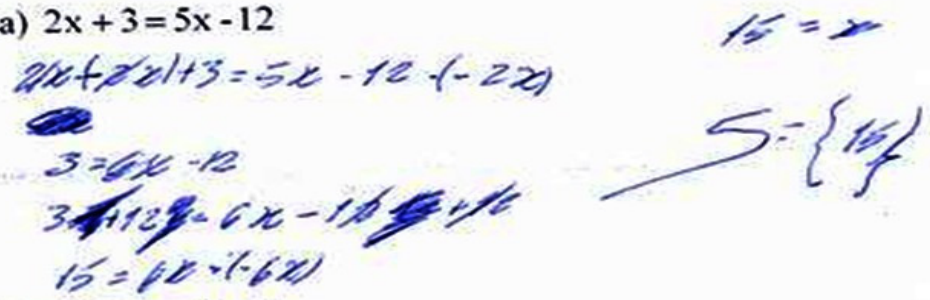

Observações sobre a solução apresentada pelo estudante:

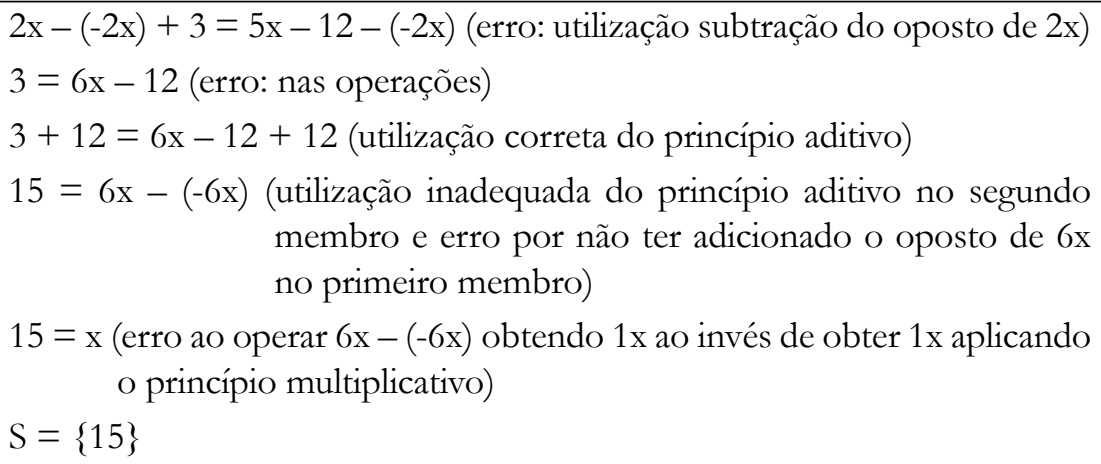

Na sequência, apresentamos o procedimento de um estudante $\left(\mathrm{E}_{8124}\right)$ que apresenta mais coerência e que, mesmo esquecendo um dos termos $(+3)$ na sua primeira equação equivalente e um $(+5 x)$ na sua terceira equação equivalente e sem demonstrar como foi realizada a transformação final, de " $-\mathrm{x}=-5$ " para em “ $\mathrm{x}=5$ ", indicou o valor correto da incógnita.

Equação: $2 \mathrm{x}+3=5 \mathrm{x}-12$

Solução $\left(\mathrm{E}_{8124}\right)$ :

\begin{tabular}{l|l|}
\hline 4) Resolva: & $\frac{1}{3} \cdot-3 x=\frac{1}{3} \cdot-15$ \\
$2 x+(-3)=5 x-12+(-3)$ & $-3 x=-15$ \\
$2 x=5 x-12-3$ & $-\frac{3 x}{3}$ \\
$2 x+(-5 x)=-15+(-5 x)$ & $x=5$ \\
$-3 x=-55$ & $x$ \\
\hline
\end{tabular}


Nesse caso específico, podemos supor que para o estudante não é necessário indicar os termos cujos opostos serão adicionados, quando da utilização do princípio aditivo. Observe-se, no entanto, que as operações foram realizadas, corretamente, considerando tais termos.

$2^{\circ}$ caso: erro nas transformações com macetes

$1^{\circ}$ exemplo $\left(\mathrm{E}_{1221}\right)$ :

Equação: $2 \mathrm{x}+3=5 \mathrm{x}=12$

Solução $\left(E_{1221}\right)$ : erro na operação $2 x-5 x$, obtendo $3 x$ ao invés de $-3 x$.

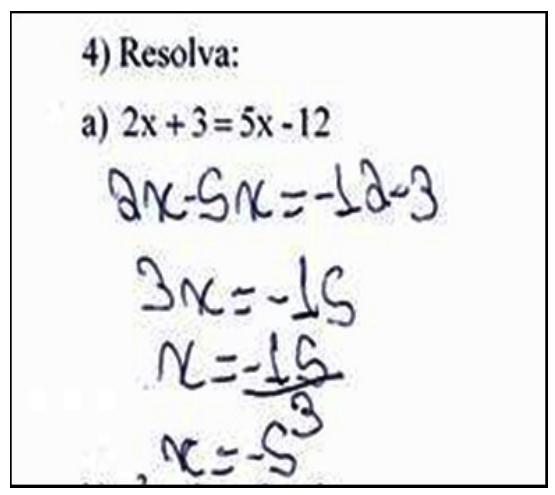

$2^{\circ}$ exemplo $\left(\mathrm{E}_{1207}\right)$ :

Equação: $2 \mathrm{x}+3=5 \mathrm{x}=12$

Solução $\left(\mathrm{E}_{1207}\right)$ : erro no macete "passando" o termo 3 para o segundo membro sem "mudar" o sinal; erro: operação $2 \mathrm{x}-5 \mathrm{x}=3 \mathrm{x}$ ao invés de $-3 \mathrm{x}$.

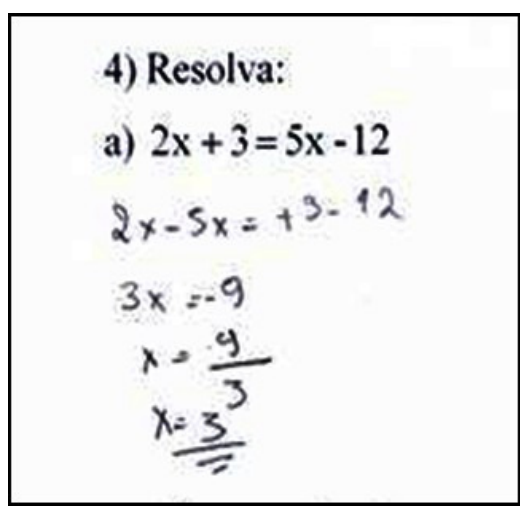

Os erros identificados entre os estudantes revelam as dificuldades dos processos de aprendizagem, mas também de ensino, podendo se constituírem em subsídios para a gestão da sala de aula. 
No estudo sobre dificuldades das crianças que se iniciam em álgebra, Booth (1995, p. 23) questiona: "Por que é difícil aprender álgebra?". O autor mostra que "uma das maneiras de tentar descobrir o que torna a álgebra difícil é identificar os tipos de erros que os alunos comumente cometem nessa matéria e investigar as razões desses erros." (BOOTH, 1995, p. 23).

Em suas pesquisas sobre análises de erros, Cury (2007, p. 63) faz referência à avaliação da aprendizagem na modalidade de provas, destacando que o “importante não é o acerto ou erro em si [...] mas as formas de se apropriar de um determinado conhecimento, que emergem na produção escrita e que podem evidenciar dificuldades de aprendizagem."

O processo mais utilizado pelos estudantes que obtiveram o valor correto para a incógnita, valendo-se de macetes, foi o seguinte:

Equação: $2 \mathrm{x}+3=5 \mathrm{x}=12$

$$
\begin{aligned}
& 2 x-5 x=-12-3 \\
& -3 x=-15(-1) \\
& 3 x=15 \\
& x=\frac{15}{3} \\
& x=5
\end{aligned}
$$

Este último exemplo é bastante significativo para estabelecermos relação entre equação e inequação de $1^{\circ}$ grau com uma incógnita. Ao transformar os dois membros da segunda equação em termos positivos, pela multiplicação por $(-1)$, deixa-se de aplicar o princípio aditivo, eliminando a possibilidade de, na inequação, evitar a ideia de que ao multiplicá-la por (-1) inverte-se o sentido da desigualdade. Ou seja, aplicando o princípio aditivo, o termo em " $\mathrm{x}$ " será positivo sem a utilização do macete "multiplica-se a inequação por (-1) e inverte-se o sentido da desigualdade", frequentemente/comumente utilizado em sala de aula, inclusive em livros didáticos. Como exemplo, verificamos que Ribeiro (2008, p. 108), ao resolver uma inequação, o faz multiplicando-a por “-1", observando o seguinte: "Note que, ao multiplicarmos ambos os membros por um número negativo, invertemos o sinal da desigualdade", sem demonstração matemática.

A multiplicação da equação por “-1" para que o termo em x fique positivo pode trazer dificuldades ou obstáculos na compreensão das inequações. O mesmo processo aplicado às equações, ou seja, utilizar o princípio aditivo ao invés de multiplicar por “-1", quando aplicado às inequações, evitaria a ideia comumente utilizada na escola de que "multiplicando-se a inequação por (-1) e inverte-se o sentido da desigualdade". Essa "regra" não é compreendida pelos estudantes da 
Educação Básica, nem mesmo por muitos dos que chegam à universidade e se deparam com inequações. Quando solicitados a demonstrar a suposta inversão do sinal da desigualdade, só conseguem mostrar a necessidade da inversão, na aritmética, pelo fato de a sentença obtida pela multiplicação por (-1) tornar-se falsa. Por exemplo, ao multiplicar a sentença $2+8>-4$ por (-1) obtém-se uma sentença falsa $(-10>4)$. Assim, é necessário inverter a ordem da desigualdade, resultando: $-10<4$. Essa lógica é muitas vezes apresentada aos alunos, com base inclusive em livros didáticos.

Exemplo ilustrativo:

$-3 x \geq-15$

$-3 \mathrm{x}+(+3 \mathrm{x}) \geq-15+(+3 \mathrm{x})$ (aplicação do princípio aditivo)

$0 \geq-15+3 \mathrm{x}$

$0+(+15) \geq-15+3 x+(+15)$ (aplicação do princípio aditivo)

$15 \geq 3 x$, ou seja,

$3 \mathrm{x} \leq 15$

É importante que os estudantes percebam que, na realidade, com a utilização do princípio aditivo, não é o sinal da desigualdade que inverte, mas o que muda é a leitura que fazemos, considerando o termo em x no primeiro membro.

Com base nos dados, podemos constatar que na Escola 1 houve preocupação em aplicar os princípios matemáticos, aditivo e multiplicativo, para resolver a equação de $1^{\circ}$ grau com uma incógnita, e na Escola 2 a resolução teve como base a aplicação de macetes.

Como já mencionado, os estudantes tiveram mais dificuldade para resolver a equação de $2^{\circ}$ grau, se comparado com a de $1^{\circ}$ grau. Dos 39 estudantes que tentaram resolvê-la, 22 se utilizaram da fórmula $x=\frac{-\mathrm{b} \pm \sqrt{\mathrm{b}^{2}-4 \mathrm{ac}}}{2 a}$, atribuída a Bháskara (ou tiveram a intenção de utilizá-la) e 17 tentaram outros procedimentos. Dos que se utilizaram da fórmula, foram identificados dois problemas: erro na própria fórmula ou erro nos cálculos. Vejamos alguns exemplos:

$1^{\circ}$ tipo: erro na indicação da fórmula

$$
\begin{aligned}
& \text { Equação: } x^{2}+6 x+9=0 \\
& x=\frac{-b^{2} \pm \sqrt{b^{2}-4 a c}}{2 a}\left(E_{8125} ; E_{8206} ; E_{8210} ; E_{8222}\right) \\
& x=\frac{b \pm \sqrt{b-4 a c}}{2 a}\left(E_{8201} ; E_{8219}\right) \\
& x=\frac{-b \pm \sqrt{b^{2}-a c}}{2 a}\left(E_{8210}\right)
\end{aligned}
$$


$2^{\circ}$ tipo: erro na fórmula e nos cálculos $\left(\mathrm{E}_{3214}\right)$ :

Equação: $x^{2}+6 x+9=0$

$$
\begin{aligned}
& \text { b) } x_{A}^{2}+\underset{B}{6 x}+\underset{C}{9}=0 \\
& \Delta=b^{2}+4 \cdot a c \\
& \Delta=6^{2}+4 \cdot 1 \cdot 9 \\
& \Delta=36+36 \\
& \Delta=72
\end{aligned}
$$

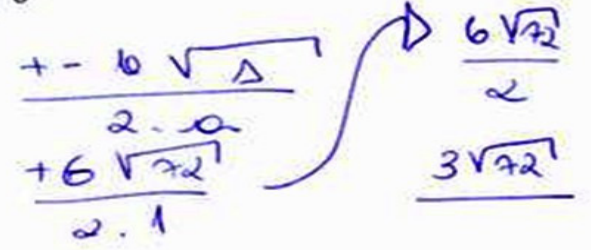

Nesse caso específico, além dos problemas de fórmula, identificamos uma dificuldade básica, que é o cálculo do valor do discriminante separadamente, podendo o estudante perder ou não construir a ideia do todo. $\mathrm{O}$ significado da palavra "discriminante" também deveria fazer parte dos objetos de ensino, para o qual parece não ter sido atribuído sentido quando analisamos esse último procedimento.

Quantos aos outros procedimentos, a maioria (10 dos 17) tem relação com o procedimento utilizado para a solução da equação de $1^{\circ}$ grau: inicialmente a ideia de "isolar" os termos com incógnita no $1^{\circ}$ membro para, em seguida, tentar determinar o valor da incógnita. Neste tipo de procedimento identificamos uma variedade de processos e resultados, conforme podemos visualizar nos exemplos apresentados, na sequência.

Equação: $x^{2}+6 x+9=0$

$1^{\mathrm{o}}$ exemplo: $\mathrm{E}_{8118}$

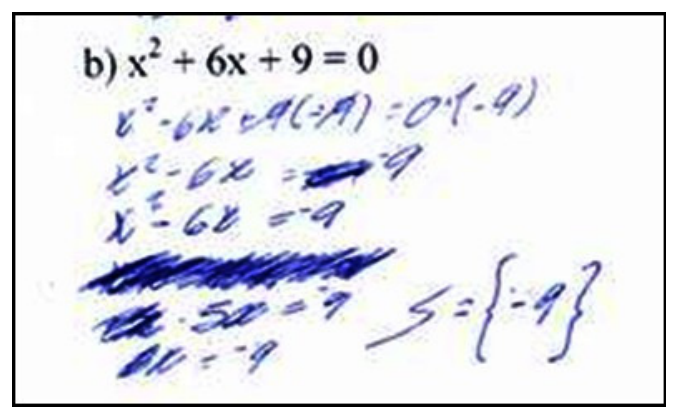


$2^{\circ}$ exemplo: $\mathrm{E}_{1203}$

$$
\begin{aligned}
& \text { b) } x^{2}+6 x+9=0 \\
& x^{2}+6 x=0-9 \\
& 7 x^{2}=-9 \\
& 49 x=-9 \quad x=5,444 \ldots \\
& x=\frac{49}{9} \quad x
\end{aligned}
$$

$3^{\circ}$ exemplo: $\mathrm{E}_{3215}$

$$
\text { b) } \begin{aligned}
& x^{2}+6 x+9=0 \\
& 7 x^{2}=-9 \\
& x^{4}=-2-2 \\
& x=\sqrt{16} \\
& x=4
\end{aligned}
$$

$4^{\circ}$ exemplo: $\mathrm{E}_{8212}$

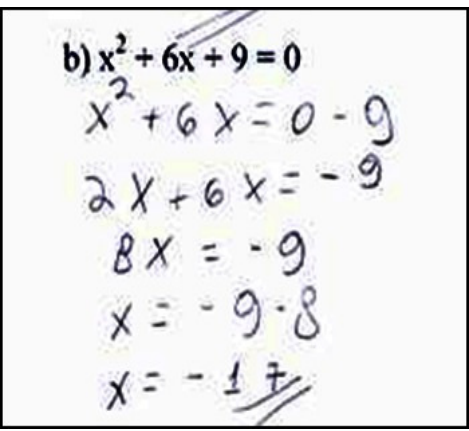

Como podemos constatar, a concepção utilizada para resolver equações de $1^{\circ}$ grau não vigorou para solucionar a equação de $2^{\circ}$ grau completa, constituindo-se em obstáculo epistemológico. Ou seja, a ideia de juntar os termos em " $\mathrm{x}$ " no primeiro membro ou "isolar o termo em x" não foi válida para a equação de $2^{\circ}$ grau em função de a incógnita estar em dois termos e com graus diferentes.

É importante perceber que, seguindo suas concepções, os estudantes "transformaram" a equação de $2^{\circ}$ grau em equação de $1^{\circ}$ grau, ou seja, o expoente de $\mathrm{x}^{2}$ foi, de alguma forma, eliminado. 
Estes procedimentos têm relação com a discussão feita por Kieran (1995) sobre equações e expressões algébricas. A autora destaca uma ideia de fundamental importância para a distinção entre aritmética e álgebra: "[...] a principal diferença entre a aritmética e a álgebra é essa distinção entre as operações utilizadas no processo de resolver equações e as operações indicadas nessas equações." (KIERAN, 1995, p. 104-105). Ou seja, para esses estudantes, o sinal da operação de adição no $1^{\circ}$ membro indicou exatamente a necessidade de operar, de alguma forma, com os termos $\mathrm{x}^{2}$ e $6 \mathrm{x}$. Nesse sentido é importante que eles percebam a diferença entre o significado do sinal de igualdade em uma sentença aritmética e o significado deste mesmo sinal em uma sentença algébrica. Significa dizer que a atribuição de sentido ao conceito de equação para poder atribuir sentido aos procedimentos utilizados para resolvê-la é fundamental no estudo da álgebra, cujo objetivo deve fazer parte explicitamente da proposta desenvolvida em sala de aula. Além disso, a identificação das semelhanças e diferenças, ou seja, das particularidades de uma equação de $2^{\circ}$ grau em comparação com uma de $1^{\circ}$ grau, é fundamental para a compreensão dos tipos de solução possíveis em cada caso.

Em relação aos objetos de saber, Chevallard (1985 apud GRANDO, 2000) os distingue de outros objetos. Refere-se a noções matemáticas, paramatemáticas e protomatemáticas. As noções matemáticas são objeto de ensino, e as paramatemáticas são noções-ferramenta da atividade matemática. As protomatemáticas dizem respeito, por exemplo, à capacidade de reconhecer a oportunidade de aplicar os conhecimentos já internalizados. Alguns exemplos colocados pelo autor como noção paramatemática são a noção de parâmetro, de equação e de demonstração. No nosso caso específico, reportamo-nos à noção de equação como uma necessidade de fazer parte explícita dos objetos de ensino.

Numa equação, além do sinal de igualdade, enfatizamos a necessidade de o estudante se apropriar do significado de incógnita e perceber o seu papel numa sentença matemática aberta e o que significa resolver uma equação. A concepção colocada por Leite, ao tratar de sentenças matemáticas, é bastante pertinente nesse contexto: "Na sentença aberta $\mathrm{x}+3=8$, o valor 5 , colocado no lugar do $\mathrm{x}$, transformaria a sentença em $5+3=8$, que é uma sentença fechada." (LEITE et al., 1968, p. 54). Essa concepção de transformação de sentença aberta em fechada amplia a visão do estudante sobre o que significa resolver uma equação de $1^{\circ}$ grau com uma incógnita e sobre o próprio processo de resolução de equações, eliminando a já conhecida expressão “ $\mathrm{x}=7$ ”, por exemplo, como resposta final de uma equação, ou mesmo de uma situação-problema com enunciado em linguagem corrente. Aqui nos reportamos também a Polya (1978), o qual contempla o retrospecto ou a verificação como a etapa final do processo de resolução de um problema. Vimos que, para um expressivo número de estudantes, 
a resolução de uma equação de $2^{\circ}$ grau constituiu-se em um problema, para o qual não conseguiram mobilizar conhecimentos adequados.

Considerando que apenas cinco estudantes conseguiram determinar as raízes da equação de $2^{\circ}$ grau e observando os erros nos diferentes procedimentos utilizados, podemos afirmar que não houve entre os estudantes que participaram da pesquisa atribuição de sentido ao conceito de equação e sua respectiva solução. Essa situação revela as dificuldades de aprendizagem desses estudantes e até mesmo os obstáculos didáticos provenientes da metodologia utilizada em sala de aula, o que denota a necessidade de um processo ensino-aprendizagem que privilegie, dentre outros aspectos, a fundamentação matemática. Grando e Marasini (2008) apresentaram os resultados de pesquisas indicando a importância de levar em consideração alguns princípios pedagógicos para a elaboração e o desenvolvimento de propostas pedagógicas, destacando-se nesse caso o domínio dos fundamentos da matemática e a importância de relacionar os novos conceitos com outros já formados, no interior de um sistema de conceitos.

É importante também destacar a visão de Cury (2007, p. 80) de que “[...] o erro se constitui como um conhecimento, é um saber que o aluno possui, construído de alguma forma, e é necessário elaborar intervenções didáticas que desestabilizem as certezas, levando o estudante a um questionamento sobre as suas respostas."

Em relação ao conteúdo de função de $1^{\circ}$ e $2^{\circ}$ graus, verificamos que o grau de dificuldade, entre os estudantes dos dois níveis de Educação Básica, é ainda mais expressivo.

Os dados mostram que para a função representada pela equação $\mathrm{y}=2 \mathrm{x}$ + 2 nenhum estudante determinou sua raiz. Quanto ao gráfico dessa função, somente estudantes de $8^{a}$ série representaram corretamente, em número de onze: oito da Escola 1 ( $\left.\mathrm{E}_{8102 ;} \mathrm{E}_{8108 ;}, \mathrm{E}_{8111 ;} \mathrm{E}_{8112 ;} \mathrm{E}_{8118}, \mathrm{E}_{8119} ; \mathrm{E}_{8121}, \mathrm{E}_{8124}\right)$ e três da escola 2 $\left(\mathrm{E}_{8204}, \mathrm{E}_{8213}, \mathrm{E}_{8220}\right)$, o que representa $11,82 \%$ do total de estudantes. Para a função de $2^{\circ}$ grau, representada pela equação $y=x^{2}+5 x+6$, apenas um estudante determinou suas raízes $\left(\mathrm{E}_{8224}\right)$, e quatro construíram o gráfico de forma correta. $\left(\mathrm{E}_{8102} ; \mathrm{E}_{8108} ; \mathrm{E}_{8111} ; \mathrm{E}_{8112}\right)$.

Do total de estudantes da Educação Básica que participaram da pesquisa, identificamos quatro que construíram de forma correta o gráfico das duas funções, todos estudantes de $8^{\mathrm{a}}$ série da Escola $1\left(\mathrm{E}_{8102 ;}, \mathrm{E}_{8108 ;}, \mathrm{E}_{8111 ;} \mathrm{E}_{8112}\right)$.

Em geral, tanto para a equação de $1^{\circ}$ grau como para a de $2^{\circ}$ grau, os estudantes construíram uma tabela de valores para determinar os pares orde$\operatorname{nados}(\mathrm{x}, \mathrm{y})$ e depois traçar o gráfico. É importante ressaltar que nas questões 
propostas não foi indicado o conjunto universo. No entanto, como os estudantes que participaram da pesquisa estavam em final de $8^{a}$ série e de $1^{\circ}$ e $3^{\circ}$ anos do Ensino Médio e, em geral, este conjunto é introduzido na $7^{a}$ série do Ensino Fundamental, para fins de análise o conjunto dos números reais foi considerado como o conjunto universo.

Uma das dificuldades mais frequentes entre aqueles que tentaram construir o gráfico das funções ocorreu nos cálculos para determinar os pares ordenados. O erro nas operações básicas impediu que vários estudantes conseguissem traçar o gráfico de forma correta.

Observamos que os estudantes da 8 a série do Ensino Fundamental da Escola 1 foram os que mais tentaram construir os gráficos, se comparados com os de $8^{a}$ série da Escola 2. Entre os estudantes do $1^{\circ}$ e do $3^{\circ}$ ano do Ensino Médio, a maioria não fez nenhuma tentativa, nem mesmo para determinar os pares ordenados.

Com isso, podemos afirmar que a maioria dos estudantes que participaram da pesquisa apresentou dificuldades para converter uma equação-função de sua representação na forma algébrica para a representação gráfica, principalmente quando se trata de uma equação-função de $2^{\circ}$ grau em relação a uma equação-função de $1^{\circ}$ grau. Sobre as representações dos objetos matemáticos, a concepção de Duval (2003, p. 21) é que "a compreensão em matemática implica a capacidade de mudar de registro." O autor ainda defende a ideia de que "a compreensão matemática está intimamente ligada ao fato de dispor de ao menos dois registros de representação diferentes." (DUVAL, 2003, p. 22).

\section{Conclusões}

Essa pesquisa revelou, mais uma vez, que os objetivos e as metas a serem alcançadas com a Educação Matemática são temas a serem debatidos no cotidiano dos cursos de formação de professores e nas próprias escolas de Educação Básica. As análises mostraram que, embora o sentimento em relação à matemática seja positivo para uma parcela significativa dos estudantes que participaram da pesquisa (67,74\%), o estudo da álgebra está longe de ser considerado satisfatório entre eles. O que se percebe é que o estudo de equações e de funções parece ser realizado valorizando somente a sua resolução, sem a realização de um estudo completo de todas as noções necessárias à compreensão dos conceitos. Além disso, os procedimentos utilizados, tanto pelos estudantes do Ensino Fundamental como pelos do Ensino Médio, deixam transparecer a ideia de que cada conceito é visto isoladamente. A falta de compreensão das relações que se estabelecem entre os conceitos que compõem o conteúdo de equação e entre os conceitos de equação e função revela o importante papel que representam as 
relações existentes entre os diferentes conceitos de álgebra, na constituição dos sistemas de conceitos. Nesse sentido, Vygotsky (1998, p. 138) afirma que

Os conceitos não ficam guardados na mente da criança como ervilhas em um saco, sem qualquer vínculo que os una. Se assim fosse, nenhuma operação intelectual que exigisse coordenação de pensamentos seria possível, assim como nenhuma concepção geral do mundo. Nem mesmo poderiam existir conceitos isolados enquanto tais; a sua própria natureza pressupõe um sistema.

Assim, a fragilidade da aprendizagem das definições iniciais da álgebra do Ensino Fundamental provoca no estudante um acréscimo de dificuldades nas definições em nível de Ensino Médio. Nesse caso específico, as dificuldades dos estudantes que já estão finalizando o Ensino Médio, em relação à álgebra, verificam-se também pelo expressivo número de estudantes que deixaram de responder às questões. É somente com o domínio do conhecimento que podemos estabelecer relações, comparar, analisar, abstrair e generalizar novos conceitos. E a apropriação de significados de novos conceitos possibilita maior domínio e controle do indivíduo perante as situações, isto é, autonomia nas decisões, o que contribui de forma significativa na qualidade de atuação no mundo contemporâneo. (VYGOTSKY, 1993).

Assim, é necessário que os estudantes aprendam matemática e possam fazer dela um instrumento para conhecer a realidade e acompanhar as rápidas mudanças que nela ocorrem. Para isso, os cursos de formação de professores precisam estabelecer, efetivamente, quais conhecimentos a escola atual necessita. As escolas, por sua vez precisam avaliar suas práticas e buscar compreendê-las teoricamente. Além disso, o mais importante, ao organizar a prática, é adequá-la aos objetivos da aprendizagem, e isso leva a pensar que a aprendizagem de conceitos mais complexos costuma esbarrar em dificuldades de conhecimentos anteriormente aprendidos ou mesmo na superação de concepções que antes eram tidas como verdadeiras e passam a ser obstáculos para as novas aprendizagens. Segundo Brousseau (1986 apud MORENO, 2006, p. 55), "a tomada de consciência 'oficial' pelo aluno do objeto de conhecimento e pelo professor da aprendizagem do aluno é um fenômeno social muito importante e uma fase essencial do processo didático: este duplo reconhecimento é o objeto da institucionalização."

Nesse sentido, alguns princípios deveriam ser definidos conjuntamente entre os educadores matemáticos para, com base nesses princípios, as propostas pedagógicas poderem ser elaboradas nas escolas. Para essa elaboração, é necessário que conheçamos melhor o pensamento dos estudantes com quem vamos conviver. Levar em consideração o que os estudantes pensam sobre a atividade de estudo, pois saber de suas concepções e expectativas pode fornecer indicati- 
vos para o estabelecimento de regras contratuais de um verdadeiro compromisso didático, porque firmado conjuntamente. (SILVA; MOREIRA; GRANDO, 1996).

Em resumo, esse estudo revelou limitações dos processos de ensino-aprendizagem da matemática desses estudantes da Educação Básica mostrando fragilidades conceituais em suas percepções/compreensões em relação à matemática escolar e seus modos de pensar em relação aos procedimentos matemáticos. Apontou também carências de conceitos e definições algébricas até mesmo pelos estudantes que estão finalizando o ensino médio. Diante disso, é urgente que seja repensado o ensino da matemática na Educação Básica para que os estudantes possam perceber a importância da álgebra para o desenvolvimento do pensamento.

Apesar das dificuldades demonstradas pelos estudantes, o estudo aponta para possibilidades de mudança na situação atual. Para isso, é necessário elaborar propostas metodológicas que considerem princípios pedagógicos fundamentados teoricamente e que despertem no estudante o desejo de aprender matemática. É um desafio que se coloca para quem está preocupado com a qualificação da Educação Matemática nas escolas da Educação Básica.

\section{Referências}

BOOTH, L. R. Dificuldades das crianças que se iniciam em álgebra. In: COXFORD, A. F.; SHULTE, A. P. As idéias da álgebra. Tradução de Hygino H. Domingues. São Paulo: Atual, 1995.

BRASIL. Parâmetros Curriculares Nacionais: Matemática. Brasília: MEC/SEF, 1998.

CURY, H. N. Análise de erros: o que podemos aprender com as respostas dos alunos. Belo Horizonte: Autêntica, 2007.

CURY, H. N.; RIBEIRO, A. J.; MÜLLER, T. J. Explorando erros na resolução de equações: um caminho para a formação do professor de Matemática. Unión - Revista Iberoamericana e Educación Matemática, v. 28, p. 143-157, dez. 2011.

DUVAL, R. Registros de representações semióticas e o funcionamento cognitivo da compreensão em matemática. In: MACHADO, S. D. A. (Org.). Aprendizagem em matemática: registros de representação semiótica. Campinas: Papirus, 2003. p. 11-33.

GRANDO, N. I. Dificuldades e obstáculos em Educação Matemática. Espaço pedagógico, Passo Fundo, v. 2, n. 1, p. 109-122, dez. 1995.

. Transposição didática e Educação Matemática. In: RAYS, O. A. Educação e ensino: constatações, inquietações e proposições. Santa Maria: Pallotti, 2000. p. 115-125.

GRANDO, N. I.; MARASINI, S. M. Educação Matemática: a sala de aula como espaço de pesquisa. Passo Fundo: Universidade de Passo Fundo, 2008. 
IFRAH, G. História universal dos algarismos: a inteligência dos homens contada pelos números e pelo cálculo. Tradução de Alberto Muñoz e Ana Beatriz Katinsky. Rio de Janeiro: Nova fronteira, 1997. v. 2.

KIERAN, C. Duas abordagens diferentes entre os principiantes em álgebra. In: COXFORD, A. F.; SHULTE, A. P. (Org.). As idéias da álgebra. Tradução de Hygino H. Domingues. São Paulo: Atual, 1995. p. 104-110.

LEITE, J. D’A. et al. Matemática: Curso Liceu. Rio de Janeiro: Editora Liceu, 1968.

MIORIM, M. Â.; MIGUEL, A.; FIORENTINI, D. Ressonâncias e dissonâncias do movimento pendular entre álgebra e geometria no currículo escolar brasileiro. Zetetiké, Campinas, n. 1, p. 19-39, mar. 1993.

MORENO, B. R. de. O ensino do número e do sistema de numeração na educação infantil e na $1^{a}$ série. In: PANIZZA, M. Ensinar matemática na educação infantil e nas séries iniciais: análise e propostas. Porto Alegre: Artmed, 2006. p. 43-76.

POLYA, G. A arte de resolver problemas. Tradução de Heitor Lisboa de Araújo. Rio de Janeiro: Interciência, 1978.

RIBEIRO, J. Matemática: ciência e linguagem, 1: Ensino Médio. São Paulo: Scipione, 2008. ROBAYNA, M. M. S. et al. Iniciación al algebra. Madrid: Sintesis, 1996.

SILVA, E. O. da; MOREIRA, M.; GRANDO, N. I. O contrato didático e o currículo oculto: um duplo olhar sobre o fazer pedagógico. Zetetiké, Campinas, v. 4, n. 6, p. 9-23, jul./dez. 1996.

USISKIN, Z. Concepções sobre a álgebra da escola média e utilizações das variáveis. In: COXFORD, A. F.; SHULTE, A. P. (Org.). As idéias da álgebra. Tradução de Hygino H. Domingues. São Paulo: Atual, 1995. p. 9-22.

VYGOTSKY, L. S. Obras escogidas II: problemas de psicología general. Madrid: Visor Distribuciones, 1993.

Obras escogidas IV: psicologia infantil. Madrid: Visor Distribuciones, 1996.

Pensamento e linguagem. Tradução de Jefferson Luiz Camargo. 2. ed. São Paulo:

Martins Fontes, 1998.

Psicologia pedagógica. Tradução de Paulo Bezerra. São Paulo: Martins Fontes, 2001.

Recebido em 11/03/2012

Aceito em 26/07/2012 